\begin{tabular}{|c|c|}
\hline S.P 2619960 angINEERING DATA TRANSMITTAL & 1. EDT NQ 613035 \\
\hline
\end{tabular}

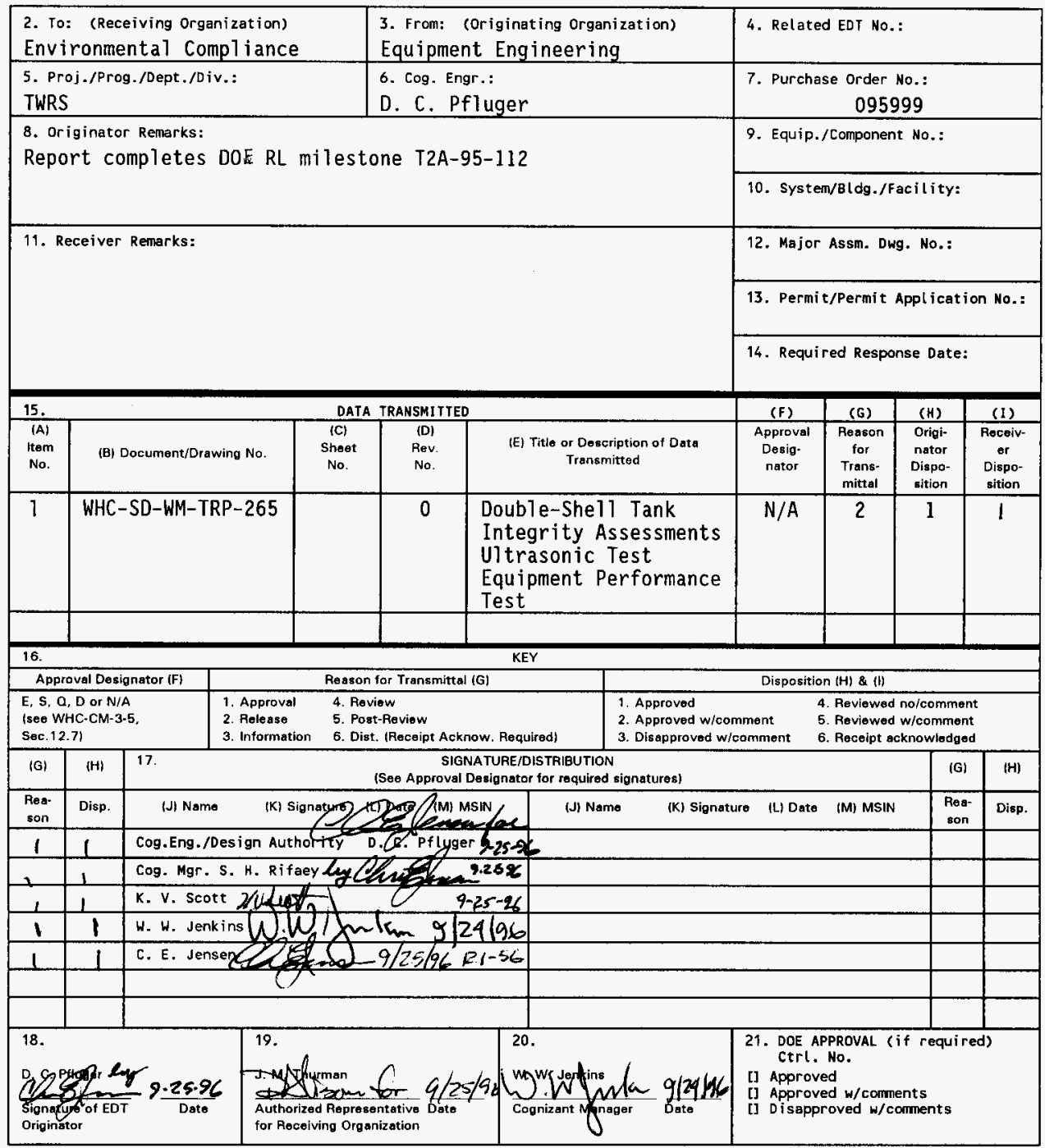

BD-7400-172-2 (04/94) GEF097 


\title{
Double-Shell Tank Integrity Assessments Ultrasonic Test Equipment Performance Test
}

\author{
D. C. Pfluger
}

Westinghouse Hanford Company, Richland, WA 99352

U.S. Department of Energy Contract DE-AC06-87RL10930

EDT/ECN: 613035

UC: 606

Org Code: $74 \mathrm{~F} 10$

Charge Code: $\mathrm{N} 1534$

B\&R Code: EW3120071 Total Pages: 38

Key Words: Flaw detection, ultrasonic examination, integrity assessment, remote equipment

Abstract: A double-shell tank inspection system was performance tested over three months until August 1995 at Pittsburgh, Pennsylvania, completing a contract initiated in February 1993 to design, fabricate, and test an ultrasonic inspection system intended to provide ultrasonic and visual data to determine the integrity of 28 double-shell tanks at Hanford. This report documents the results of tests conducted to evaluate the performance of the inspection system. The results indicate the system requires additional development and testing before deployment in the double-shell tanks.

TRADEMARK DISCLAIMER. Reference herein to any specific comercial product, process, or service by trade name, trademark, manufacturer, or otherwise, does not necessarily constitute or imply its endorsement, recommendation, or favoring by the united states Government or any agency thereof or its contractors or subcontractors.

Printed in the United States of America. To obtain copies of this document, contact: WHC/BCS Document Control Services, P.O. Box 1970, Mailstop H6-08, Richland WA 99352, Phone (509) 372-2420; Fax (509) 376-4989.
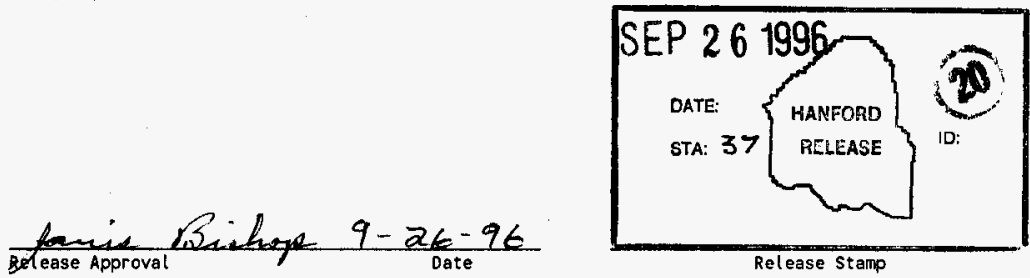
WHC-SD-WM-TRP-265, Rev. 0

\title{
DOUBLE-SHELL TANK INTEGRITY ASSESSMENTS \\ ULTRASONIC TEST EQUIPMENT PERFORMANCE TEST
}

\author{
Author \\ D. C. Pfluger \\ September 20, 1996
}


WHC-SD-WM-TRP-265, Rev. 0

CONTENTS

1.0 INTRODUCTION . . . . . . . . . . . . . . . . . . . . . 1

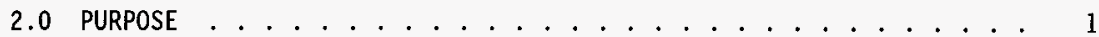

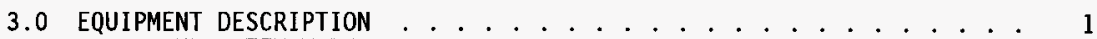

3.1 SUBSYSTEM MODULES $\ldots \ldots \ldots$. . . . . . . . . . . . . . . . . .

3.2 SUBSYSTEM COMPONENTS . . . . . . . . . . . . . . . . . . 3

4.0 TEST DESCRIPTION . . . . . . . . . . . . . . . 3

5.0 TEST RESULTS ...................... 4

6.0 CONCLUSION ......................... 4

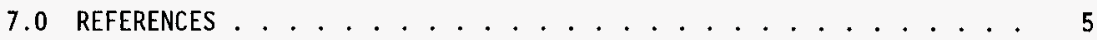
APPENDIXES

A. PERFORMANCE TEST RESULTS .................. . . . . . . .

B. RESOLUTION ACTIONS RECOMMENDED BY CONTRACTOR . . . . . . B-1

C. UT RESULTS ...................... . . . . 
WHC-SD-WM-TRP-265, Rev. 0

This page intentionally left blank. 


\author{
WHC-SD-WM-TRP-265, Rev. 0 \\ DOUBLE-SHELL TANK INTEGRITY ASSESSMENTS \\ ULTRASONIC TEST EQUIPMENT PERFORMANCE TEST
}

\title{
1.0 INTRODUCTION
}

A double-she11 tank (DST) inspection (DSTI) system was performance tested over three months until August 1995 at Pittsburgh, Pennsylvania, completing a contract initiated in February 1993 to design, fabricate, and test an uitrasonic inspection system intended to provide uitrasonic test (UT) and visual data to determine the integrity of 28 DSTs at Hanford. The DSTs are approximately one-million-gallon underground radioactive-waste storage tanks. The test was performed in accordance with a procedure (Jensen 1995) that included requirements described in the contract specification (Pfluger 1995).

\subsection{PURPOSE}

This report documents the results of tests conducted to evaluate the performance of the DSTI system against the requirements of the contract specification. The test of the DSTI system also reflects the performance of qualified personnel and operating procedures.

\subsection{EQUIPNENT DESCRIPTION}

The examination equipment consists of a remotely controlled robotic mechanism mounted with cameras and ultrasonic probes that is inserted in the annulus space between the primary and secondary tanks of a DST. The equipment is controlled through cables that connect the robotic mechanism with the mobile control center (trailer) outside the tank farm fence. An artist's conception of the DSTI system's deployment configuration in the tank farms is shown in Figure 1.

The DSTI system includes the following major sub-system modules and components.

\subsection{SUBSYSTEM MODULES}

The Mobile Control Center (MCC) provides a central location for the operation of the robotic control system and collection of ultrasonic and visual examination (VT) data. The MCC consists of an office trailer, robot operator console, UT console, VT console, and back-up generator. The MCC can be located up to 500 feet from the tank access risers.

The deployment module (DPM) supports deployment and operation of the robotic inspection system. The DPM consists of a housing, electrical enclosure, and pneumatic distribution system. 
$N^{\prime \prime}-C-S D-W M-T R^{D}-265$, Rev. 0

Figure 1. DSTI System's Deployment Configuration.

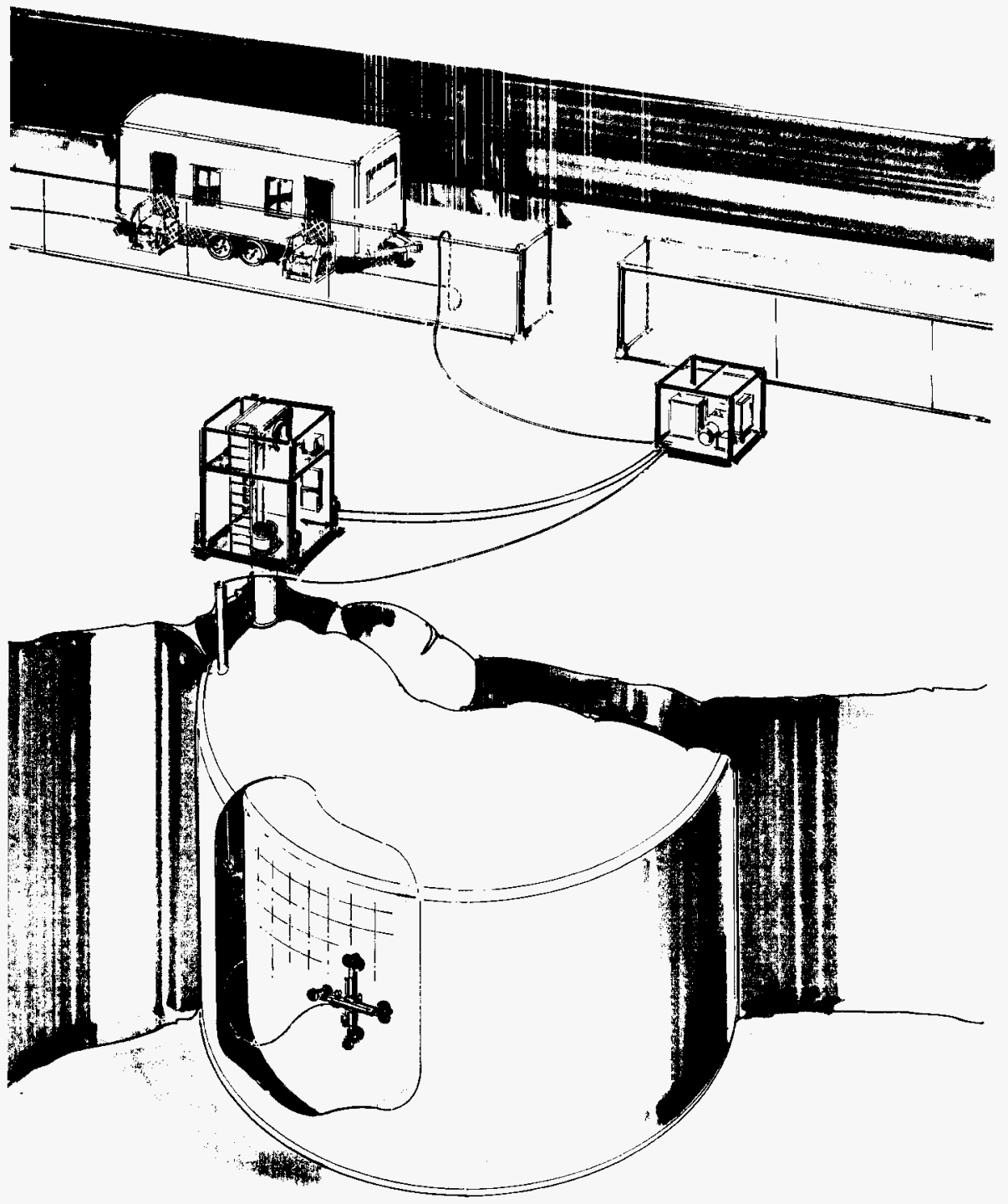

REDZDNE

Double Shell Tank

Inspection System 
The cable management assembly (CMA) is used to lower the scan carriage (robot mechanism) into the tank annulus. The CMA consists of a structural frame to support the robot and its components, the tether reel to manage tether feed to the robot, the cable hoist to raise and lower the robot, a grapple mechanism to couple and decouple from the hoist cable, and the couplant supply system.

\subsection{SUBSYSTEM COMPONENTS}

The robotic mechanism performs visual examination and UT inspection of the primary tank and secondary tank liner walls and the primary tank lower knuckle and bottom (via air slots in the tank foundation) using two different tooling packages. The sub-systems include the vehicle, which deploys the cleaning and inspection tools: the tank wall inspection package which includes the tooling for cleaning, VT, and UT of the tank; and the knuckle and air slot inspection package, which includes the tooling for cleaning, VT, and UT of the primary tank knuckle and bottom.

The robotic mechanism is two beams connected to make an ' $X$ ' shape. Each beam has opposing pneumatic cylinders at each end that press against the opposing tank walls. The crawler moves by alternately extending the cylinders (pneumatically) for one beam, retracting the cylinders for the other beam, and then driving the released beam relative to the fixed beam using electric motors at the intersection of the two beams.

The purpose of the UT system is to measure tank wall thickness, and to detect and size corrosion pitting and stress-corrosion cracking. The UT system consists of the U1trasonic Testing Console, P-Scan U1trasonic System, tank wall UT array module (TWUTAM), and a knuckle/air slot transducer array module (KASTAM).

The VT system has the capability to examine the primary and secondary tank, lower primary tank knuckle, and primary tank bottom via the air slots. The purpose of the VT system is to evaluate the surface condition, monitor cleaning and UT operations, provide video image feedback to the robot positioning systems, provide navigation data, and provide a general area overview to assist during robot movements.

\subsection{TEST DESCRIPTION}

The test sequence was organized into sections with individual checklists to document each test step (Jensen 1995). These sections included basic functions (e.g., deployment, cleaning, VT, UT, retrieval, etc.). The sections were arranged to progress through a simulated inspection of the mockup during normal and abnormal operations. A specification requirement to perform one DST inspection in 36 hours led to an expected duration of one week for the testing.

The test was performed at the contractor's facility using their mockup of a DST annulus. The 12-foot-ta11, seven-degree section of mockup consisted of the following: (1) 3-inch, 4-inch, and 24-inch risers; (2) one cooling pipe simulating all but AY and AP DSTs; (3) six conduits on the secondary tank liner; (4) variable annulus width (from 26 to 34 inches); (5) three slots of 
WHC-SD-WM-TRP-265, Rev. 0

different geometries with concrete bottoms; and (6) a 12-foot long section simulating double-rolled lower knuckles and an upper haunch.

During testing, the contractor was able to block out most of the ambient light. Testing was performed at room temperature. The full length of transmission cables were used to simulate real tank inspections. The robot mechanism operated with a chain connecting it to a hoist to prevent damage to the mechanism in case it slipped or fell to the annulus floor. The chain was always kept slack to keep it from assisting or hindering test performance.

Ten specimens containing defects were used to test the performance of the UT system. They were presented to the contractor with the inside surface and specimen identification obscured (i.e., a blind test).

\subsection{TEST RESULTS}

The testing was performed over a three month period around a recurrent pattern of one to two weeks of testing followed by repairs. The performance test check-off sheets were too cumbersome to use because testing was frequently stopped for adjustments and repairs, and followed by retesting. The testing was performed incrementally depending on the functions that were operational at the time. The test procedure was used as an accounting list to ensure that all functions were considered for testing. Some functions were not retested after failed attempts to repair the equipment. Several configurations/functions were not tested.

The VT system performance was satisfactory. The UT system with the TWUTAM performed adequately and the UT analyst was able to work with Westinghouse Hanford Company (WHC) and Pacific Northwest National Laboratory (PNNL) to resolve most of the deficiencies (Appendix C). The robot mechanism was able to negotiate the annulus obstacles in the mockup. The clearance to deploy and retrieve through a 24-inch riser in Hanford's 28 DSTs was well demonstrated through a 22-inch inside-diameter riser.

The problems related to reliability were of numerous origins (e.g., electrical, mechanical, and software). Every attempt to retrieve the robot mechanism from the annulus during abnormal operation (planned or unplanned) was stopped for assistance or aborted. Some detailed requirements and the detailed results of the performance test are in Appendix A.

\subsection{CONCLUSION}

The DSTI system requires additional development and testing before deployment in the double-shell tanks. The system did not perform satisfactorily in nine of seventeen tests. The most notable exceptions concern fail-safe recovery and system reliability. The system did detect and size flaws on the straight portion of the primary tank wall and detect flaws on the primary tank bottom. 
After the test, WHC representatives met with the contractor on September 19 and 20, 1995, to evaluate the readiness to ship the DSTI system to Hanford, Washington. The system was demonstrated using the mockup available. The demonstration was intended to simulate a typical tank inspection. The demonstration was stopped several times to make adjustments and recover from system failures.

Before the DSTI system can be deployed, the deficiencies noted in this performance test report must be resolved and the 31 modifications the contractor identified (Appendix B) to improve the system's performance must be considered. The DSTI system was delivered to Hanford to allow WHC more control over its development and to more effectively manage the cost and schedule to complete the remaining work.

Subsequent to delivery, WHC reviewed alternatives and developed a strategy to perform DST inspections (Scott 1996). The selected strategy is to obtain a commercial inspection service to perform a reduced scope of inspections. The DSTI system will be held in storage and be reconsidered if the inspection service is unsuccessfur.

\subsection{REFERENCES}

Jensen, C. E., 1995, Double-Shell Tanks Inspection System Performance Test Procedure, WHC-SD-WM-ATP-113.

Pfluger, D. C., 1995, Double-Shell Tank Ultrasonic Inspection Performance Specification, WHC-S-4108.

Scott, K. V., 1996, Double-She7l Tank Integrity Examination In-Process Review, WHC-SD-WM-PD-047. 
WHC-SD-WM-TRP-265, Rev. 0

This page intentionally left blank. 
WHC-SD-WM-TRP-265, Rev. 0

APPENDIX A

PERFORMANCE TEST RESULTS 
WHC-SD-WM-TRP-265, Rev. 0

This page intentionally left blank. 
WHC-SD-WM-TRP-265, Rev. 0

\section{REQUIREMENTS}

The following requirements can be found in more detail in Pfluger (1995).

The contractor will provide the examination system, calibration and certification documentation of equipment and standards, test personnel, and qual ification/certification documentation.

The scan carriage must be capable of separately or concurrently transporting a video camera, light source, UT sensor head, and tank surface cleaning tool. Speed and direction of the scan carriage shall be controlled remotely from the mobile equipment station.

Visual examination of the tank walls must be achieved using a video camera and light source. The minimum coverage of the field of view is a 5 -inch by 5 -inch area centered on the UT examination zone. The camera system also must be capable of viewing up to 5 feet from the examination zone and in all directions parallel to the tank surface (forward, behind, left and right of the examination tool). Video data will be stored on magnetic tape.

The UT sensor head must be capable of measuring wall thickness, and detecting and measuring the depth of corrosion pitting, and detecting and measuring the length and depth of stress corrosion cracking oriented primarily parallel or perpendicular to the welds. Top, side, and end view images of the scan area will be displayed coincident with the position and camera display. The position of the UT head relative to the weld and along the axis of the weld is required and must be recorded with the UT data. UT data will be displayed in real time. UT data collected will be stored digitally on a removable medium.

\begin{tabular}{|l|l||}
\hline \multicolumn{1}{|c|}{ ITEM } & \multicolumn{1}{|c|}{ REQUIREMENT/VALUE } \\
\hline \hline $\begin{array}{l}\text { Examination extent as basis to } \\
\text { measure ability to inspect one tank } 36 \text { hours }\end{array}$ & $\begin{array}{l}\text { 1) Examine the primary tank } \\
\text { following a continuous weld pattern } \\
\text { of vertical and horizontal } \\
\text { directions cross over the annulus } \\
\text { and perform a straight 1ine vert ical } \\
\text { examination for wall thickness and } \\
\text { pitting of the secondary wal1; } \\
\text { 2) remove the equipment and instal1 } \\
\text { it through a riser. }\end{array}$ \\
\hline $\begin{array}{l}\text { Installation \& removal of scanner } \\
\text { from tank annulus }\end{array}$ & \begin{tabular}{l} 
Fail safe \\
\hline Personnel certification
\end{tabular} \\
\hline
\end{tabular}




\begin{tabular}{||l|l||}
\hline \multicolumn{1}{|c|}{ REQUIREMENT } & \multicolumn{1}{|c|}{ VALUE } \\
\hline \hline Video camera resolution & $\begin{array}{l}370 \text { horizontal, 350 vertical lines } \\
\text { or greater }\end{array}$ \\
\hline Horizontal position accuracy & \pm 1.0 -inch \\
\hline Vertical position accuracy & \pm 1.0 -inch \\
\hline Wall thickness measurement accuracy & \pm 0.0025 inch \\
\hline
\end{tabular}

\begin{tabular}{|c|c|c|}
\hline Condition & $\begin{array}{l}\text { Minimum Dimension } \\
\text { to be Characterized }\end{array}$ & Accuracy \\
\hline Pitting & $0.7 \mathrm{t}$ diam. $\times 0.35 \mathrm{t}$ deep $^{(2)}$ & \pm 0.020 inch \\
\hline $\begin{array}{l}\text { Cracks (axial and } \\
\text { circumferential) }\end{array}$ & $\begin{array}{c}t \text { long } \times 0.5 t \text { deep } \\
0.2 t \times 12 \text { inches long }\end{array}$ & $\begin{array}{l} \pm 0.050 \text { inch (depth) } \\
\text { and } \\
\pm 0.5 \text { inch (length) }\end{array}$ \\
\hline
\end{tabular}

1 - $t$ is the nominal tank wall thickness

2 - pits are on the tank inside surface and have a hemispherical shape

\section{GENERAL EXCEPTIONS}

The following items are exceptions to the PERFORMANCE TEST RESULTS described later in this appendix.

- A contractor employee, who was not the operator, was allowed to view the test with communication hardware to warn the operator before the system could be damaged. The operator declared his intentions, waited for a warning, and then proceeded with the test item. The operator quickly started relying on this form of communication instead of using the camera monitors for navigation, which compromised the intent to simulate a tank inspection, but significantly increased the speed of the testing.

- The contractor did not maintain change control of the inspection system in accordance with applicable procedures.

- Operation procedures were redlined by the contractor during the testing. To increase the speed of the testing, retesting to modified procedures was not performed.

- The contractor took exception to flaw detection and sizing requirements for outside-diameter-connected flaws.

- The checklists from the performance test procedure were not used to increase the speed of the test. During the testing, there were numerous test stoppages that would have required many incident reports and resolution meetings that would have significantly extended the performance test schedule. 
WHC-SD-WM-TRP-265, Rev. 0

- There are six configurations of telescoping cylinders and transducer array modules: (1) examine the primary tank with telescoping cylinders for all DSTs except AP Tank Farm using the tank wall ultrasonic transducer array module (TWUTAM); (2) same as 1) using the knuckle airslot transducer array module (KASTAM) instead of the TWUTAM; (3) examine the secondary tank liner with telescoping cylinders for AP Tank Farm using the TWUTAM; (4) same as 3 ), but examine the primary tank; (5) same as 4), but using the KASTAM; and (6) same as 3 ), but using telescoping cylinders for all DSTs except AP Farm. The two sets of telescoping cylinders are necessary to negotiate air supply (cooling) pipes in AP tanks that are located near the secondary tank liner, unlike the other 22 DSTs, which have their pipes near the primary tank. Only configurations 1), 2), and 3) were tested.

\section{PERFORMANCE TEST RESULTS}

The results from testing are described below and referenced by the applicable section in the performance test procedure (Jensen 1995). The narrative below is provided in lieu of using the checklists in the test procedure. A statement of specific exception is followed by "Exception."

- SYSTEM PRE-DEPLOYMENT (REF. SECTION 9.1) - To decrease the testing time, the contractor did not perform functional checks in accordance with applicable procedures. Some cursory checks were made at the contractor's discretion. All other test items in this section were completed satisfactorily.

- DEPLOYMENT (REF. SECTION 9.2) - The deployments and retrievals were through a 22-inch inside-diameter riser cut to the approximate shape depicted on Hanford drawings. The left (when facing the primary tank) $x$-foot would not unstow by rotation. Exception. In all cases, test personnel looked down the riser to aid deployment (and later retrieval). Exception. A camera to remotely view down the riser is recommended.

- PRIMARY TANK WALL CLEANING (REF. SECTION 9.3) - Cleaning four inches on each side of a 20 -inch long weld was timed at 12 minutes. The cleaning brush operated at an angle, which cleaned one side of a vertical weld better than the other-more testing or modification may be required. The TWUTAM cleaning brush reaches down to just 2 inches above the upper tangent of the lower knuckle. Exception. The navigation error was tested: horizontal $(x)-X: 37.3$ to $X: 132.3$, measured 94.25 with tape measure, yielding .75 inch error; vertical $(y)-Y: 45.8$ to $Y: 99.3$, measured 54.75, yielding 1.25 inch error. Exception.

- $\quad$ PRIMARY TANK WALL VT INSPECTION (REF. SECTION 9.4) - Inspection camera view of 5 inches by 5 inches was confirmed. Five inches of tank wall is represented by 7.75 inches on the screen. This testing was sat isfactory.

- PRIMARY TANK WALL UT EXAMINATION (REF. SECTION 9.5) - No false calls were made (i.e., calling an unflawed grading unit flawed), and in all cases, the detection for all required flaws was tested satisfactorily. There were several discrepancies between the measurements made by the contractor and measurements made by PNNL (manufacturer) to determine the 
depth and length of cracks in the test specimens. The results of a review (Appendix C) resolved all but one discrepancy. The detection and sizing of cracks is therefore, considered satisfactory. The measurement of wall thickness by the contractor did not meet the requirement for accuracy. Exception. WHC has acknowledged that the accuracy requirement of \pm 0.0025 -inch for wall thickness may be waived. The contractor demonstrated an accuracy of \pm 0.006 inches. The sizing of corrosion pitting was tested satisfactorily.

- SECONDARY TANK WALL CLEANING (REF. SECTION 9.6) - The tank wall cleaning was satisfactory.

- SECONDARY TANK WALL VT EXAMINATION (REF. SECTION 9.7) - The inspection camera view of 5 inches $\times 5$ inches was confirmed. Five inches of tank wall is represented by 6.5 inches on the screen. Lighting was adequate and this testing was satisfactory.

- SECONDARY TANK WALL UT EXAMINATION (REF. SECTION 9.8) - The UT signal was periodically lost. Exception. The TWUTAM couplant flow rate was determined as $100 \mathrm{~mL}$ in 1:47 minutes, yielding .89 gallons/hour.

- $\quad$ PRIMARY TANK BOTTOM CLEANING (REF. SECTION 9.9) - The cleaning brush leaves lines on the contact area. Constant force on the curved section was hard to achieve. Additional effort is required to clean large areas. There was no brush contact in the tapered slot. Exception.

- PRIMARY TANK BOTTOM VT EXAMINATION (REF. SECTION 9.10) - There was no visibility. The overview camera was used, however it was lowered to a depth below its reach by design, taking advantage of the short height of the mockup. Exception. The inspection camera exhibited screen noise that will need to be reduced or eliminated. Both the overview camera and inspection camera demonstrated resolution satisfactorily.

- PRIMARY TANK BOTTOM UT EXAMINATION (REF. SECTION 9.11) - The KASTAM reaches approximately 18.5 inches past the tangent where the tank bottom begins. The KASTAM stuck in the 1.5 by 1.5 -inch square slot due to a pinch roller failure. The igus chain broke and remained attached by the wiring harness. The clutch was slipping. This affected the indexing of position however, the presence of flaws were detected. The KASTAM's couplant flow rate was determined as $100 \mathrm{~mL}$ in $1: 47.43$ minutes. Changeout of TWUTAM to KASTAM was timed at 1:06 hours.

- COOLING PIPE NEGOTIATION (REF. 9.12) - The location of the pipe in AY tanks was not simulated. The maximum clearance was measured and is insufficient to negotiate the pipes in AY DST annuli. Exception. The DSTI configuration to negotiate the pipe location for AP tanks was not tested to speed up the testing. All configurations tested did negotiate six conduits satisfactorily.

- HAUNCH NEGOTIATION (REF. 9.13) - Access to the haunch was 1 imited and consequently not tested. Exception.

- POWER RECOVERY (REF. 9.14) - After several attempts, this was tested as satisfactory. 
- ROBOT RECOVERY (REF. 9.15) - Two recovery configurations were tested. With bottom foot affected, the telescoping cylinder was (1) retracted by air supply failure, the robot mechanism walked with the extended foot sliding against wall; and (2) extended by air supply failure, the robot mechanism slipped some when braced only by the top 2 feet. No retrieval was possible. Exception. General area camera almost caught on lower edge of riser. The procedure was changed to rotate the scan carriage so the camera can be viewed by the overview camera. A second overview camera was recommended. The left $x$-foot would not stow. Later, after other movements, it did stow.

- DATA COLLECTION, RECORDING, DiSPLAY AND STORAGE (REF. 9.16) - All data collection, recording, display, and storage requirements were demonstrated satisfactorily.

- ERROR MESSAGES (REF. 9.17) - The error messages were not specifica11y tested. However, many error messages were demonstrated satisfactorily during the testing.

\section{REFERENCES}

Jensen, C. E., 1995, Doub7e-She7l Tanks Inspection System Performance Test Procedure, WHC-SD-WM-ATP-113, Westinghouse Hanford Company, Richland, Washington.

Pfluger, D. C., 1995, Double-Shel7 Tank U7trasonic Inspection Performance Specification, WHC-S-4108, Westinghouse Hanford Company, Rich 1 and, Washington. 
WHC-SD-WM-TRP-265, Rev. 0

This page intentionally left blank. 
WHC-SD-WM-TRP-265, Rev. 0

APPENDIX B

\section{RESOLUTION ACTIONS RECOMMENDED BY CONTRACTOR}


WHC-SD-WM-TRP-265, Rev. 0

This page intentionally left blank. 


$$
\text { WHC-SD-WM-TRP-265, Rev. } 0
$$

\section{Introduction}

This document is the initial draft of the cost estimate for the DSTI system improvements. The tasks have been grouped inlo three categories - Failure Modes, Reliability Issues, and Performance Improvements. Each task is described and solutions for each task are presented. Some of the tasks oullined have more than one solution. Cost information is provided for ench options separately. This gives us a cost range for the completion of each task By summing the lower and higher estimates separately, an overall cost estimate range can be gencralcd for the entire system.

\section{Failure Modes}

\section{Rotary Joint Drive}

The current design of the rotary joint drivetrain does not allow this axis to backdrive in the event of a molor failure. There is currently a 66:I gearhead mated to a 50:1 gearhead which in turn drives a 15:1 worm gear set (total reduction - 49,500:1). Due to the intemsl friction of the gearsets and the large amount of reduction a very large amount of torque is needed to allow the motor to backdrive. Should the rotary joint motor fail, this axis is locked inro position, making it impossible to retrieve the robot from the annulus. There are a couple of possible solurions to this problem

One solution involves designing some sort of brcakaway coupling for the motor. This coupling would be undone with long-handled tools while the robot is still in the annulus. This could prove to be a very tedious operation in the field and would also compromise the integrity and strength of the drivetrain. This is probably lhe lowest cost option.

Another solution involves changing out the current motor and gearhead to a larger motor with less gar reduction. Tesis have been done on the DSII sysiem during the initial build phase which showed that the mator could be backdriven when the 66:1 gearhead ras not in the system (750:1 total gear ratio). If this gearbead were not in the system, a motor of sufficient low RPM torque would have to be used lo drive this axis (12 in-lb @ $62 \mathrm{pm}$ ) at the same speed. The power requirements of a motor this size may be too great for the existing amplifier circuitry. The cost fot this option is higher than the first.

Another solution would be to reduce the torque requirements of the motor. By reducing the torque needed, the existing motor could be used without the 66:1 gearhead. The only way to reduce the required corque is to only use the rotary axis when the $X$ and $Y$ axes are at or near their midpoint. This eliminates the large cantilevered load condition which crists when the slides are al one of their endpoints. This overhung load is currently handled by servoing the motor/gearhead combination. A brake would have to be incorporated into the drivetrain to carry this overhung load. The brake would lock the rotary joint in position when the $X$ and $Y$ slides are going uhrough their full range of motion. This brake would also have to tum off in the event of a power loss. This would allow the robot to be folded should the brake lose electrical power. This option requires some major redesign of the rotary joint mechanism. Electrical power would also have to be supplicd to the brake. This is the highest cost option.

\section{Pneumatic System}

A complete review of the pneumatic system needs to occur for fail-safe issues. The final impact of this review cannot be known at this time but a worst case example for estimating purposes prould be to install a rcdundart pneumatic system, including airlines, valving, fittings, and electrical connections. The pnewnatic failures of imponanee deal rith preventing the robot from falling and always allowing the robot to be relricyed. As it turns out, these two goals sometimes work against each other during the design and implementation of the system. The options and tradooffs will be further reviewed and a plan will be approved and implemented based on this review.

The review will include the following ilems:

- Improvement of the in-line connectors

- Foot cylinder extend/return - redundant valves, return spring 


$$
\text { WHC-SD-WM-TRP-265, Rev. } 0
$$

- Foot locking mechanism - review need for locks in light of new deploy/retrieve method

- Fool tolate mechanism - redundant valves, return spring

- UT head deployistow - redundant vaives, cylinder, renum spring

This review is expecled lo lake 4 days with the end resull being a work plan for the pneumatic system modifications.

\section{DPM Pncumatic Logic}

There are currently two air supply lines nunning from the DPM through the slipring at the CMA, and down the tether to the robot One of these lines supplies air pressure lo the $\mathrm{X}$-slide and the ather line supplies pressure to the Y-slide. These two lines are joined at the robot through a logic network consisting of two crossover lines and a series of check valves. This logic allows one air line to poprer the robot if the other line loses pressure. Whan this happens, the operator must go to the DFM and manually shut of the air line with no pressurc. At a minimum, gauges need to be installed so that the operator koows which line to close.

Another option is to install pneumatic "fuses" at the DPM which automatically shut off the line that loses pressure. These fuses are fairly simple, consisting of a pilot-operated valve, a cleeck valve, and a manual three-way valve which rescis the fuse. This option eliminates opcrator enor in shutting one of the air lines and is also aclualed automatically long beforc the operator could shut the valve mamually.

\section{Wiring Harness}

A complete rrview of the piring harness necds to occur for fail-safe issues. The final impact of this review cannot be known at this time but a worst case example for estimating purposes rould be to insall a completely redundant wiring hamess. The wiring failures of importance deal with preventing the robot from falling and always sllowing the robot to be retrievod As it tums out, these two goals sometimes work against cach other during the design and implementation of the system. The options and tradeoffs will be funher revicwed and a plan will be approvod and implemented based on this revicw.

The review will include the following itens:

- Potcntiometer reference board removal

- $X$ and $Y$ slide motors - redundant wising

- Secondary slide motor - redundant wiring

- Rolary joint motor - redundant riring

- Scissor jack - redundant wiring

- UT head deploy/stow - redundant wiring

This review is cxpected to take 4 days with the end result being a work plan for the wiring hamess modifications.

\section{Chiller Flow Switch}

The original design of the system incorporated a flow/comperahure monitoring circuil for the water chiller that cools the linear power amplifiers in the DPM The flow switch in this circuit needs to be replaced with anolier model which is more scnsilive to the low flow ratc which is used.

\section{CMA Hoist}

The initial design of the DSTI systern estimated a weight of the scan carriage of $200 \mathrm{lb}$. The actual weighi is on the order of $500 \mathrm{lb}$. The robot hoist in the CMA was specified using the initial weight estimale. While the winch is not undersized for a $500 \mathrm{Ib}$ load, much of the safety factor has "dissppeared" due to the increase in robot weight. Docurnentation exists from the hoist vendor stating that the hoist is adequate, but it is our recommendation that it be changed out to at least a tro ton (4000 lb) model. 


$$
\text { WHC-SD-WM-TRP-265, Rev. } 0
$$

A review will be performed of all failure modes of the system. A list of specific items that have already been identified is included below. This list also outlines some solutions and cost estimates for those solutions. This review may also reveal additional items that need to be addressed.

The review will include (but is not limited to) the following itens:

- Secondary slide backdrivability

- $X$ and $Y$ slide belts - roller chain drive, genr drive

- General area camera mounting - breakaway mounting plate

- Scissor jack motor - return spring

- Airslot tooling - breakaway couplings

\section{Reliability Issues}

\section{Airslot Drive}

The current design of the airslot tooling drive mechanism does not provide adequatc driving force or reliable indexing of the tooling in the airslots. There are two possible solutions for this problem One solution involves remaling the driven chain out of a stiffer material (aluminum). Teeth could be machined into the aluminum which would provide a more positive drive than the currenl plastic chain. The other component that would have to be replaced arc the drive clutches. The current clutches Hork well under ideal conditions but do not transmit an adequate amount of torque ro allow the looling to be driven reliably in air slots with rough concrete or wavy tank bottoms. A larger clutch with more drive espability aeeds to be incorporated into the existing design This option allows most of the existing tooling to be reused with some modification. While these changes will improve the drive reliability, conditions may exist that will prevent the tooling from driving at all (due to the clutch slipping). This option is expensive because of the amount of design, manufacture, and assembly time required for the aluminum chair.

The other option for improving the reliability of the airslot drive is to design and build a new tooling package. The proposed design consists of three linear ballscrew slides mounted in parallel. Ench slide has a different $100 \mathrm{l}$ mounted on it. A separate motor is used to direedly drive each slide. Instead of using clutehes to choose a tool, relays are used to select a drive motor. The slides are mounted to the secondary slide and are stowed in a vertical position while the robot during deploy/retrieve/Fralking modes. A tilt mochanism is used to deploy the slides to a horizontal position. This tilt mechanism uses the sane motor that currently drives the knuckle tilt mechanism. No addilional wiring; or controls are needed to implement this option. This option is more expensive than the first because of additional cngineering time and increased parts cost. Despite the increased cost, this option should result in a much more reliable tooling platform.

\section{Airslot Feedback}

The position feedback on the airslot drive mochanism is currently an encoder on the drive motor. This method is usually adequatc in a dited drive mechanism but is not adequate here because of slippage in the drive train. The clutch is a source of error because it does slip when its output torque is excecded The pinch roller/gear tooth drive mechanism is another source of error due to skipping of the gear teeth On the existing design, a possible solution is to measure the position of the tooling where the chain exils the housing. This could be accomplishod by mounting a linenr potentiometer (string pot - like those used on the $X$ and $Y$ slides) to the airslol housing. The string is then artached to the chain near the end effector. The current sysem provides feedback for only one tool drive (UT). Should position feedback be required on all three tools, this would impact the electronies and wiring. A relay network could be incorporated to allow for reading of one potentiomctcr al a time.

If the linear siide design is implemented, three potentiometers would also need to be used. These could be linear (string) pots that measure stide position, or encoders that measure motor position. A relay nelwork could be incorporated to allow for reading of one potcatiometer at a time. 


$$
\text { WHC-SD-WM-TRP-265, Rev. } 0
$$

\section{Grapple Latch Verification}

There is currently no feedback to tell when the grapple mechanism is attached to the robot. This is a potcntially dangerous sinuation which could cause the robot to be accidentally dropped During qualification testing of the system, it was determined that if a ring were painted on the grapple, the operator could detemuine from the overview camera if the grapple is successfully attached or not. This verification ring will be implemented.

\section{Payload Wiring}

The current design or the robol includes twa different tooling packages which need to be exchanged depending on which part of the lank is to be inspected. During qualifieation lesting. it was observed that this tool exchange procedure could be simplified if the tooling packages were wired differently. Currently, the robot wiring hamess ends at the tooling. All connectors for the tooling have to be packaged at the tooling. where there is already very little room The proposed change consists of hardwiring a "pigtail" inside of a cable tray (IGUS chain) onto each tooling package. This pigtail is custom designed for each tooling package and is long enough to locale the connector bundle on the body of the robol, not on the tooling. By doing this, the secondary slide drive motor has to carry less reight (no connectors), and each cable tray carries fewer conductors. This also saves space on the tooling packages because there is no connector bundle. The tooling swap also becomes much simpler because the design is more modular.

\section{Performance Improvements}

\section{Inclinometer}

In order to know if the scan carriage is walking level with the ground or at some skewed angle the operator must perform a machine vision update. The relative orientation of the slides is available from the potentiometcrs but the absolute orientation is only available from the vision system. An inclinometer will be added to the horizontal slide to provide this orientation on a continuous basis. Although this feature is not necessary to perform an inspection, it will improve on the safely and speed of operating the robot

This improvement impacts the system from the robot all the way back to the trailer. The inclinometer mur be mounted on the horizontal slide. Enough spare lines must be found in the tether to make this possible also. A sparc VO chanacl (if it cxists) will be used to read the signal and send it to the trailer. Soltware modifications must be made to the main control code in order to read and display this channel. This could also affect the touchsercen solware, the ROBCAD model and/or the vision system code, based oll where the informalion is used.

\section{Microphone Amp Wiring}

There is a broken conductor in the robot wiring hamess that supplies the microphone amplifier board This wirc has been lagged by RedZone and needs to be replaced This will significantly reduce the level of noise in the system including the camcras and the clectronics.

\section{Tank Wall Cleaning Brush}

The testing that has been performed to date has shown that the tank wall cleaning system needs to be improved. The current course of action is to implement a tight angle drive for the cleaning motor and use an abrasive flapper wheel. This type of eleaning system is currently used to perform manual inspections. A flapper wheel is also not as sensitive to disance from the wall as the current wire brush is. This should prevent the air motor from stalling and also provide deeper and more uniform cleaning. The fixpper wheel is usually positioned perpendicular to the weld being cleaned. Because of this, it may be necessary to retrieve the robot and rotate the flapper wheel 90 degrees in order to adequatcly clean both horizontal and verical welds. Testing will be performed to determine whedher this is necessary. 
WHC-SD-WM-TRP-265, Rev. 0

\section{Secondary Slide}

The eurrent design of the sccondary slide provides adequaic force to lift the tooling packages but the motor does not have sufficient torque to drive the slide under abnomal loading conditions. This is due to internal fricrion in the slide and the design of the slide irself. Since each stage of the slide is "cantilevered" from the previous stage, and the tooling is cancilevered off of the slide, the forces on the slide bearings are much grealer than those on the tooling package. When the forces on the slide bearings become too large, the slide stalls due to the increased frictional forces. A possible solution to this problem is to replace the current slide with a ballscrem driven linear slide. This slide would have rails with linear ball bearings to reduce the internal friction of the slide and increase the cantilevered load carrying capacily.

The other problem rith the secondary slide is that it does not backdrive to a safely sowed position. Again this is due to the gear reduction in the drivetrain and the internal friction of the slide mechamism itself. This would also be solved by using rails, linear ball bearings and a ballscrew drive,

A third problem rith the slide is that, ritb the airslot tooling mounted, the stowed position of the secondary slide is when the slide is al its upper 510p. Should the slide motor fail, the stide would drive downward to its lower stop. In this position, the airslot tooling prevents the lower foot from stowing, which in turn prevents the robot from fitting through the riser. This problem needs to be addressed during the review of the airslot tooling.

\section{Cleaning Tool Contact in Large Slot}

The elcaning lool for the 2.5 in square airslots requires a thicker standoff (foot) to allow the cleaning brush to come in contact with the tank bottom. This foor will be designed and fabricated.

\section{IGUS Chain Attachments}

The wiring hamess on the robot is housed in plastic IGUS chain cable urays. The altachment points for these chains come apart periodically when the robot is moved through it's range of motion. This occurs party due to the fact that the chain is plastic and somewhat flexible, and partly due to the large amount of wiring housed in the cable trays. Metal versions of this chain exist and can be fit to the robot if there is room for a slightly larger tray. If there is not enough room, the existing chain can be sirengthened by drilling out the existing pivot points and using melal pins. This is tedious but kecps the chain in the same space envelope.

\section{General Area Camera}

The general area cancra is curronuy mounted in a position phere it can be damaged when retracting the robot through the riser. The camcra could also prornde frenough to prevent the robot from fitring in the riser altogether. Because of this, the general area camera will be mounted in a more recessed position near its current position

The camera will also be mounted on a plastic breakaway plate to allow for failsafe retrieval of the robot Should the pan and till mifunction when the camera is not stowed, the breakaway mounl will shear when the camcra comes in contact with the riser during retrieval. This bracket nceds to be designed and fabricated.

\section{Secondary Wall Foot Brackets}

The robot foor brackets used while inspecting the secondary tank wall do not currenuly provide the correct geometry for the robot to walk smoothly in the annulus. When making a transition from standing on the horizontal to the vertical feet, the entire robot moves in a direction perpendicular to the tank wall. While this does not prevent the robot from being able to walk, it does raise the risk of the robot slipping donnward in the annulus. The solution to this problem is to adjust the brackets for the secondary tank 


$$
\text { WHC-SD-WM-TRP-265, Rev. } 0
$$

wall. This does not mean that the brackets need to be remade. The existing brackets can be modified in order to implement this solution.

\section{Rear Foot Mount Shaft}

The current sobot feel are somewhat longer than the inipial design. Testing bas show th that these feet slill allow the robot to fit through the riser, but it is a very close fit In order to gain a litie more room when deploying and retrieving the robot, the rear feet of the robot will be shorened to the dimension of the original feet. This requires very linte modification to the fect

Before inplemenling this clange, some adritional testing should be performed. It would be advaneageous to leave the feet longer because it gives more of a safety margin when walking in the annulus. Testing at RedZone has verified that the fect do function properly in the annulus. Additional testing should be performed at WHC to delermine if this design is adequate for all conditions (narrower or wider annulus, traversing obstacles).

\section{KASTAM RTD}

The lemperature probe (RTD) in the KASTAM is currently not functioning. While this does not prevent the robol from being able to collect UT data, it rould be usefil to acquire a temperature map with UT data. Futhermore, temperature monitoring is required to cnsure that the temperature is below $200 \mathrm{deg}$. $F$ when acquiring UT data. The RTD will be repaired and a minor design change will be implemented prior to operation to prevent another failure.

\section{UT Delivery System}

Although the performance is satiffactory, a quick review of the UT delivery system will be performod for potential improvemens. Items such as contact pressure, contact angle, stifiness, and control will be addressed. The end result of this review will be documentation of the UT delivery system and a work plan for any necessary modifications.

\section{VXWorks Compiler}

A VXWorks compile environment will be installed on the DSTI system compurers to allow for in-house revisions to the main controller soliware. This does require the purchase of a VXWorks compiler which is not included in this cost estimate. It is Raytheon's understanding that WHC pill provide this compiler.

\section{Vision System Update Process}

The vision system update process is cumbersome because of the need to toggle the robot fect during the update. The update process rill be revised to eliminare the nect for this foot toggle. It may be feasible to allow the operator to interact with lie process using the mouse to accept/reject poinis lound by the vision system. This could improve the speed and accuracy of the process. Training may be required for this but is not included in the budget at this time.

\section{ROBCAD Graphics}

The ROBCAD three dimensional model of the robot and tank have been implemented There are however a few problems with the model that need to be addressed. These modifications are listed below:

- Make the model easicr 10 load (more user friendly)

- Make the model motions match the robot motions

- Add weld maps to model(s)

The estimated time to implement these modifications is four man-wieeks.

\section{Warning Messages}




$$
\text { WHC-SD-WM-TRP-265, RE!v. O }
$$

The water chiller and temperature/low scusing system currently provide no feedback to the operaror as the status of the system. The amplifier circuitry shuts down automatically when the temperature of the fluid gets too high for safe operation of the amplifiers. It is desirable to know the stanus of the system because this would let the operator know if the linear amplifiers are operating normally or about to shut down. A status messige could be provided to the operator provided there are enough I/O channels available on the controller.

Another option is to mount a status light on the roof of the DPM that flashes when the linear amplifiers are energized and operating nomally. This status light could be the type found on cmergency vehicles or plant machinery. This allows the operator to know' if the amplificrs arc operating githout the complexity of modiffying tie clectronics and system soltware.

\section{Anti-nlias Fulter}

The spare anti-alias filter board that has been ordered from RedZone was built at a lower frequency. This ncw design should lor'er the noise in the servo loops and possibly in the UT signal. This board needs to be installed.

\section{Climate Control in CMA}

The issue of climate control in the CMA involves both equipment protection and personnel confort Heaters may be necessary in the CMA in the winter in order to keep the couplant in the supply hoses and tether from freezing or becoming too viseous. Henters would also provide a more comforable workspace should there be a necd for some maintenance in the CMA. Insulation and scaling would geed to be added to the CMA in order to keep the hearing and cooling requirements as low as practical.

\section{Climate Control in DPM}

Climate control in the DPM is needed mosty for personnel comfort. This is a difficult task to implement due $w$ the fact that the DPM is well ventilared to the outside. This ventilation is needed to provide adequate air how to the compressor intakes. The cicetrical enclosure has its onn climate control system as part of the original design. Most of the other components can operate safely in the temperature range specified. Onc component, the compressor motor starter does need to be in a temperature controlled housing. These electronics arc morc sensitive to temperature extremes than the other components in the DPM. This motor starter is a critical part of the sysiem because it starts the compressor when the system is operating on the back-up generator.

The other item that needs to be addressed is the air conditioning exhaust vent The AC currently exhausts inside the DPM. Ductwork needs to be installed to vent this exhaust to outside the DPM These exhaust vents are the single larges heat souree in the DPM, causing observed temperatures in the DPM in excess of 110 deg. $F$.

\section{CMA Camera}

Performance testing of the DSTI system showed that it is scarly impossible to retrieve the robot from the annulus without some view of the robol from the riser. The addition of a CMA camera could provide this view. Remote focus and z.00m features are also desirable so that the robot can be vicwed during deployment and retrieval. This modification requires a camera with zoom and focus, pan and ilt, camera controller in the trailer, another moxitor in the trailer and cabling from the trailer to we CMA.

Another desirable feature is a remote monilor in the CMA that gives the overview camera view. This would also aid in the recovery of the robot from the annulus.

\section{Overview Camera Reach}


WHC-SD-WM-TRP-265, Rev. 0

Additional reach is required for the overview camera so that it can provide a better view of the robot when performing airslot inspections. This requires longer cabling and additional mast sections. These parts will be supplied by $R$ J. Electsonies and installed by Raytheon personncl.

\section{Overview Camera Reel}

The tilt speed of the overview camera is prohibitively slow, which could cause the operator to ignore this camera because it takes too long too maneuver. The solution wo this is to increase the diameter of the reel used to wind up the tilt cable. By increasing this diameter, the speed of the tilt axis will be increased

\section{Assembly and Testing}

The assembly and testing portions of this work will be as previously budgard 
WHC-SD-WM-TRP-265, Rev. 0

APPENDIX C

UT RESULTS

C-1 
WHC-SD-WM-TRP-265, Rev. O

This page intentionally left blank. 
Date November 27, 1995

R. Ferris

S. Pitman

To Daniel Pfluger

File/LB

From Jerry Posakony

Subject Raytheon Depth Modifications

Joel Harrison Faxed me changes in values for depth of the SCC cracks using the modified algorithm that was discussed when he and Dave King were here. The list below modifies the list sent to you on November 20, 1995.

Specimen 14DW001 (Sample Plate \# 4)

\begin{tabular}{ccccccccc}
\multicolumn{3}{c}{ PNNL Record } & \multicolumn{3}{c}{ Raytheon Record } & \multicolumn{2}{c}{ Differences } \\
Location & Length & Depth & Location & Length & Depth & Length & Depth \\
TL & $4.2^{\prime \prime}$ & $0.16^{\prime \prime}$ & C1 & $3.8^{\prime \prime}$ & $0.14^{\prime \prime}$ & $0.4^{\prime \prime}$ & $0.02^{\prime \prime}$ \\
BL & $1.9^{\prime \prime}$ & 0.3 & C2 & $1.9^{\prime \prime}$ & $0.25^{\prime \prime}$ & -- & $0.05^{\prime \prime}$ \\
out & $1.8^{\prime \prime}$ & $0.37^{\prime \prime}$ & C3 & $1.4^{\prime \prime}$ & $0.30^{\prime \prime}$ & $0.4^{\prime \prime}$ & $0.07 "$
\end{tabular}

Specimen 14DW002 (Sample Plate \# 6)

\begin{tabular}{cccccccc}
\multicolumn{3}{c}{ PNNL Record } & \multicolumn{3}{c}{ Raytheon Record } & \multicolumn{2}{c}{ Differences } \\
\hline Location & Length & Depth & Location & Length & Depth & Length & Depth \\
TL & $3.25^{\prime \prime}$ & $0.43^{\prime \prime}$ & C3 & 3.5 & $0.40^{\prime \prime}$ & $0.25^{\prime \prime}$ & $0.03^{\prime \prime}$ \\
BTL & $5.5^{\prime \prime}$ & $0.34^{\prime \prime}$ & C2 & $5.9^{\prime \prime}$ & $0.31^{\prime \prime}$ & $0.4^{\prime \prime}$ & $0.03^{\prime \prime}$ \\
BR & $2.0^{\prime \prime}$ & $0.3^{\prime \prime}$ & C1 & $2.0^{\prime \prime}$ & $0.28^{\prime \prime}$ & --- & $0.02^{\prime \prime}$
\end{tabular}

Specimen 12DW003 (Sample Plate \# 11)

\begin{tabular}{cclcccccc}
\multicolumn{3}{c}{ PNNL Record } & \multicolumn{3}{c}{ Raytheon Record } & \multicolumn{2}{c}{ Differences } \\
\hline Location & Length & Depth & Location & Length & Depth & Length & Depth \\
TL & $1.6^{\prime \prime}$ & $0.22^{\prime \prime}$ & C1 & $2.0^{\prime \prime}$ & $0.225^{\prime \prime}$ & $0.4^{\prime \prime}$ & 0.005 \\
BL & $0.7^{\prime \prime}$ & Shallow & C4 & $0.9^{\prime \prime}$ & $0.06^{\prime \prime}$ & $0.2^{\prime \prime} \cdot$ &.-- \\
C & $5.1^{\prime \prime}$ & 0.55 & C3 & $5.3^{\prime \prime}$ & $0.47^{\prime \prime}(a)$ & $0.2^{\prime \prime}$ & $0.08^{\prime \prime}$ \\
TR & $1.9^{\prime \prime}$ & $0.37^{\prime \prime}$ & C2 & $1.8^{\prime \prime}$ & 0.33 & $0.1^{\prime \prime}$ & $0.04^{\prime \prime}$ \\
BR & $1.6^{\prime \prime}$ & $0.28^{\prime \prime}$ & C5 & $1.1^{\prime \prime}$ & $0.25^{\prime \prime}$ & $0.5^{\prime \prime}$ & $0.03^{\prime \prime}$
\end{tabular}

(a) Per Raytheon Fax of $11 / 21 / 95$ - - The original depth they recorded $\left(0.065^{\prime \prime}\right)$ is still considered valid as this was the depth recorded using the OD Creeping wave transducer. The 52 degree depth using crack tip diffraction technique is 0.47 ".

Reviewers Comment: The difference recorded between the crack tip and the creeping wave techniques is to be worked out at a later time. 
November 27, 1995

Page 2

\section{Specimen 12DW005 (Sample Plate \# 13)}

\begin{tabular}{cccccccc}
\multicolumn{3}{c}{ PNNL Record } & \multicolumn{3}{c}{ Raytheon Record } & \multicolumn{2}{c}{ Differences } \\
\hline Location & Length & Depth & Location & Length & Depth & Length & Depth \\
BL & $1.3^{\prime \prime}$ & 0.05 & C3 & $1.2^{\prime \prime}$ & $0.056^{\prime \prime}$ & $0.1^{\prime \prime}$ & $0.006^{\prime \prime}$ \\
C & $6.1^{\prime \prime}$ & 0.38 & C2 & $6.0^{\prime \prime}$ & $0.36^{\prime \prime}$ & $0.1^{\prime \prime}$ & $0.02^{\prime \prime}$ \\
TR & $3.2^{\prime \prime}$ & $0.25^{\prime \prime}$ & C1 & $2.9^{\prime \prime}$ & $0.30^{\prime \prime}$ & $0.3^{\prime \prime}$ & $0.05^{\prime \prime}$
\end{tabular}

I will plan to discuss this information with you when you return after the Holiday.

G. J. Posakony 
November 20, 1995

Daniel C. Pfluger

Westinghouse Hanford Company

Mail Stop H5-52

Richland, WA 99352

Dear Mr. Pfluger:

Subject: $\quad$ Meeting with Staff of Raytheon Relating to Characterization of SCC Crack Specimens

A meeting was held on November 14, 1995 to review results of the ultrasonic nondestructive examinations (NDE) performed on a series of specimen steel plates containing stress corrosion cracks. These specimens were made by Pacific Northwest National Laboratory and were ultrasonically characterized by Raytheon and Pacific Northwest National Laboratory.

Attending the meeting were:

Mr. Daniel Pfluger - Westinghouse Hanford

Mr. David King - Raytheon Engineers and Constructors

Mr. Joel Harrison - Raytheon Engineers and Constructors

Mr. Robert Ferris - Pacific Northwest National Laboratory

Mr. Gerald Posakony - Pacific Northwest National Laboratory

Meeting Objective

The objective of the meeting was to review the NDE results of the depth and length measurements reported by Raytheon and Pacific Northwest National Laboratory, and attempt to resolve measurement discrepancies found in the data between the two organizations.

\section{Background}

As part of the program to ensure the integrity of the double-shell, waste-storage tanks at Hanford, Westinghouse contracted Raytheon to provide the robotic ultrasonic inspection station for detecting and characterizing SCC, general corrosion, pitting, and wall thickness changes that might be present in the tanks. As part of the Westinghouse program, Pacific Northwest National Laboratory developed a series of steel test specimens designed to simulate various conditions that might be present in the wall of the tank. 
Daniel C. Pfluger

November 20, 1995

Page 2

Of particular importance to the meeting of November 14 were the series of four specimen plates containing SCC that Pacific Northwest National Laboratory developed. While other types of potential defects were discussed, the meeting focused on differences in the ultrasonic characterization of the depth and length of SCC in the four plates.

The specimen were initially fabricated from 1.1225-inch thick carbon steel plates. EDM notches were cut in the plates to act as crack starters. Environmental chambers were attached to the plates and stress was applied to initiate and propagate the growth of SCC. Different lengths of EDM notches were used so as to provide cracks of different lengths and depths. During the time the SCC cracks were being grown, Pacific Northwest National Laboratory made ultrasonic measurements to track the progress of cracking. Once the desired crack depths and lengths were achieved, the plates were machined to remove the EDM notches and flatten the plates. As some warpage occurred during heating, machining was necessary to achieve uniform thicknesses. Following this, ultrasonic measurements were made to define the crack depths and lengths of the finished plates. Optical and penetrant examinations were also performed to define the crack lengths observed at the surface. As part of its January 23, 1994 report, Pacific Northwest National Laboratory included a table that described length and depth dimensions of the SCC cracks. Westinghouse used this table to evaluate the measurements reported by Raytheon during the initial validation of their robotic inspection system.

Discrepancies were noted between the results of the two teams. Of particular note were the differences recorded in plate 12DW003, but there were differences in all of the plates that exceeded the specification which called for depth measurements within Meeting with Staff of Raytheon Relating to Characterization of SCC Crack Specimens \pm 0.05 inches and length measurements within \pm 0.5 inches. While the two NDE groups were using similar ultrasonic technology for making measurements, differences remained unresolved.

\section{Westinghouse Action}

In an attempt to resolve the issues, Westinghouse established a task with Pacific Northwest National Laboratory to provide an independent review to investigate and determine the source of the discrepancies. A review was made of all the original data, information was sought from individuals making the ultrasonic tests, and discussions were held with staff of Raytheon. The results of the investigation are summarized as follows:

1. Raytheon used their robotic system with a long cable between the ultrasonic system and the transducer which simulated the type of inspection that would be performed on the double-shelled tanks. Pacific Northwest National Laboratory made measurements under laboratory conditions. Some differences in results 
Daniel C. Pfluger

November 20, 1995

Page 3

should be expected, but it was felt that such differences should not have exceeded the specifications set for the inspection.

2. A request was made that the plates be returned to Pacific Northwest National Laboratory and that a repeat examination be performed to ensure that the data provided to Westinghouse in Pacific Northwest National Laboratory's report of January 25, 1995 was correct.

3. The review of data in Pacific Northwest National Laboratory's laboratory . notebooks showed that the depths reported by Pacific Northwest National Laboratory on plate 12DW003 were in error. The depth measurement data in their table inadvertently included the depth of the EDM notch. Since the EDM notch depths were typically 0.2 inches deep, the Pacific Northwest National Laboratory report indicated the cracks were at least 0.2 inches deeper than actual.

4. Raytheon and Pacific Northwest National Laboratory were requested to review all their measurements to determine if the original analysis could be confirmed. This resulted in some changes but more importantly it indicated the need for changes in analysis procedures used for making size determination. These were incorporated into subsequent data analyses.

5. Even after the re-evaluation of measurement data, differences were found which exceeded the limits defined by the specification. Since both parties were using similar analysis procedures, a face to face meeting was recommended to determine if changes in analysis might decrease the measurement differences. This resulted in the meeting held on November 14, 1995.

\section{Meeting Results}

The first step in the meeting with Raytheon was to identify those measurements that had the widest variation. Raytheon brought with them disks of all the images and data recorded during their validation studies. Pacific Northwest National Laboratory had the records and images produced by their studies. A review of the revised data showed a definite convergence, but there were still length and depth variations in a number of the cracks.

Raytheon discussed their P-Scan ultrasonic inspection system and described the two analysis protocols used for measuring length of cracks. One is known as "image coded" and the other as "level coded". For their length measurements, Raytheon had used the image coded 
Daniel C. Pfluger

November 20, 1995

Page 4

protocol. By using their data records but shifting to the level coded protocol, all but one of the length measurements were within the limits of the length measurement specification.

A comparison of the revised Raytheon and Pacific Northwest National Laboratory length and depth values for the stress corrosion cracks in four specimen plates is given below.

Specimen 14DW001 (Sample Plate \#4)

PNNL Record

Location

TL

BL

Out
Raytheon Record

Location Length Depth

C1

$3.8^{\prime \prime}$

$0.12^{\prime \prime}$

C2

C3 $1.9^{\prime \prime} \quad 0.2^{\prime \prime}$

$1.4^{\prime \prime}$

$0.265^{\prime \prime}$
Differences

Length Depth

$0.4^{\prime \prime} \quad 0.04^{\prime \prime}$

-- $0.1^{\prime \prime}$

$0.4^{\prime \prime}$

$0.105^{\prime \prime}$

Specimen 14DW002 (Plate \#6)

PNNLRecord

Raytheon Record

Differences

Location Length Depth Location Length Depth Length Depth

$\begin{array}{rlllllll}\text { TL } & 3.25^{\prime \prime} & 0.43^{\prime \prime} & \text { C3 } & 3.5^{\prime \prime} & 0.38^{\prime \prime} & 0.25^{\prime \prime} & 0.05^{\prime \prime} \\ \text { BTL } & 5.5^{\prime \prime} & 0.34^{\prime \prime} & \text { C2 } & 5.9^{\prime \prime} & 0.265^{\prime \prime} & 0.4^{\prime \prime} & 0.075^{\prime \prime} \\ \text { Out } & 2.0^{\prime \prime} & 0.3^{\prime \prime} & \text { C1 } & 2.0^{\prime \prime} & 0.25^{\prime \prime} & --- & 0.05^{\prime \prime}\end{array}$


Daniel C. Pfluger

November 20, 1995

Page 5

Specimen 14DW003 (Plate \#11)

\begin{tabular}{cccccccc}
\multicolumn{3}{c}{ PNNL.Record } & \multicolumn{3}{c}{ Raytheon Record } & \multicolumn{2}{c}{ Differences } \\
Location & Length & Depth & Location & Length & Depth & Length & Depth \\
TL & $1.6^{\prime \prime}$ & $0.22^{\prime \prime}$ & C1 & $2.0^{\prime \prime}$ & $0.175^{\prime \prime}$ & $0.4^{\prime \prime}$ & $0.045^{\prime \prime}$ \\
BL & $0.7^{\prime \prime}$ & Shallow & C4 & $0.9^{\prime \prime}$ & $0.08^{\prime \prime}$ & $0.2^{\prime \prime}$ & -- \\
C & $5.1^{\prime \prime}$ & $0.55^{\prime \prime}$ & C3 & $5.3^{\prime \prime}$ & $0.4^{\prime \prime}$ & $0.2^{\prime \prime}$ & $0.15^{\prime \prime}$ \\
TR & $1.9^{\prime \prime}$ & $0.37^{\prime \prime}$ & C2 & $1.8^{\prime \prime}$ & $0.205^{\prime \prime}$ & $0.1^{\prime \prime}$ & $0.175^{\prime \prime}$ \\
BR & $1.6^{\prime \prime}$ & $0.28^{\prime \prime}$ & C5 & $1.1^{\prime \prime}$ & $0.185^{\prime \prime}$ & $0.5^{\prime \prime}$ & $0.095^{\prime \prime}$
\end{tabular}

Specimen 12DW005 (Plate \#13)

\begin{tabular}{cccccccc}
\multicolumn{3}{c}{ PNNL Record } & \multicolumn{3}{c}{ Raytheon Record } & \multicolumn{2}{c}{ Differences } \\
Location & Length & Depth & Location & Length & Depth & Length & Depth \\
BL & $1.3^{\prime \prime}$ & $0.05^{\prime \prime}$ & C3 & $1.2^{\prime \prime}$ & $0.215^{\prime \prime}$ & $0.1^{\prime \prime}$ & $0.165^{\prime \prime}$ \\
C & $6.1^{\prime \prime}$ & $0.38^{\prime \prime}$ & C2 & $6.0^{\prime \prime}$ & $0.166^{\prime \prime}$ & $0.1^{\prime \prime}$ & $0.214^{\prime \prime}$ \\
TR & $3.2^{\prime \prime}$ & $0.25^{\prime \prime}$ & C1 & $2.9^{\prime \prime}$ & $0.243^{\prime \prime}$ & $0.3^{\prime \prime}$ & $0.007^{\prime \prime}$
\end{tabular}

Overview

By their nature, SCC are inherently difficult to size ultrasonically. While detection of the presence of SCC cracks is relatively easy, the crack morphology produces many reflectors that must be critically analyzed to determine the crack length and depth. Prior to the meeting, detailed studies were made of the data recorded from the four SCC specimens. This resulted in some changes in the values previously reported. As noted, Specimen 12DW003 included transcription errors in the Pacific Northwest National Laboratory record of depth measurements. This was identified as part of the investigation and resolved part of the issues on this particular plate. Resolving these and changing measurement protocol for length measurements resulted in a significant convergence of the reported values so that the differences related primarily to depth measurements. 
At the close of the meeting, the depth sizing procedures followed by the analysts from Raytheon and Pacific Northwest National Laboratory were reviewed. A difference in the analysis algorithm was identified that may reduce the differences in depth measurement, but further evaluation will be required before conclusions are reached.

Considering that one series of measurements were made using a remotely controlled robotic inspection station and one was made in the laboratory, the results obtained are very good. A further refinement of the procedures used for analyzing the information from SCC can well bring all measurements within the specification listed for detection and sizing of SCC.

While the values for length and depth measurements are converging, there remains the question whether these values are the actual sizes of the cracks.

\section{Euture Plans}

Two action items were suggested as a result of the meeting. The first involves a repeatability test to verify the ability of the data acquisition system and data analysis algorithms to provide like results. A test procedure is proposed to provide these data. The Raytheon remote system will be used for this experiment, and Pacific Northwest National Laboratory will provide the test parameters.

The second action item is to provide a destructive/nondestructive comparison of the depths estimated using the ultrasonic system with the actual depth of cracks. The plan proposed is to select one of the specimen plates, document the depth of two or three cracks in the plate and core sections at the location that crack depth estimates were made. These sections will be broken open and actual depths will be measured. This will provide valuable data on the accuracy of the inspection system and provide evidence and documentation that recorded data correctly describes the actual length and depth of the SCC cracks.

Yours truly,

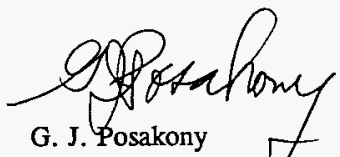

Technical Program Nanager

Engineering and Analytic Sciences Dept.

\section{$\mathrm{GJP} / \mathrm{cs}$}




\section{DISTRIBUTION SHEET}

\begin{tabular}{|c|c|c|c|c|c|}
\hline \multirow{2}{*}{$\begin{array}{l}\text { To } \\
\text { Environmental Compliance }\end{array}$} & \multirow{2}{*}{\multicolumn{3}{|c|}{$\begin{array}{l}\text { From } \\
\text { Equipment Engineering }\end{array}$}} & \multirow{2}{*}{\multicolumn{2}{|c|}{$\frac{\text { Page } 1 \text { of } 1}{\text { Date }}$}} \\
\hline & & & & & \\
\hline \multirow{2}{*}{\multicolumn{4}{|c|}{$\begin{array}{l}\text { Project Title } N \text { ork Order } \\
\text { COMPLETION OF MILESTONE T2A-95-112, DST INTEGRITY ASSESSMENT - } \\
\text { UT EQUIPMENT PERFORMANCE TEST }\end{array}$}} & \multirow{2}{*}{\multicolumn{2}{|c|}{$\begin{array}{l}\text { EDT No. } 613035 \\
\text { ECN No. }\end{array}$}} \\
\hline & & & & & \\
\hline \multicolumn{2}{|l|}{ Name } & $\begin{array}{l}\text { Text } \\
\text { With All } \\
\text { Attach. }\end{array}$ & Text Only & $\begin{array}{l}\text { Attach./ } \\
\text { Appendix } \\
\text { Only }\end{array}$ & $\begin{array}{l}\text { EDT/E } \\
\text { On }\end{array}$ \\
\hline \multirow[t]{2}{*}{$\begin{array}{l}\text { Correspondence Control } \\
\text { D. Al ison } \\
\text { B. G. Erlandson } \\
\text { J. E. Geary } \\
\text { W. W. Jenkins } \\
\text { C. E. Jensen } \\
\text { H. L. Mckinney } \\
\text { J. K. McClusky } \\
\text { W. C. Miller } \\
\text { D. C. Pfluger } \\
\text { M. L. Ramsay } \\
\text { S. H. Rifaey } \\
\text { M. J. Royack } \\
\text { K. V. Scott (2) } \\
\text { A. B. Sidpara } \\
\text { T. S. Smith } \\
\text { J. M. Thurman } \\
\text { J. E. Truax } \\
\text { A. M. Umek } \\
\text { E. J. Walter } \\
\text { Central Files }\end{array}$} & $\begin{array}{l}\text { A3-01 } \\
\text { R1-51 } \\
\text { R2-36 } \\
\text { S5-07 } \\
\text { S2-24 } \\
\text { R1-56 } \\
\text { S5-10 } \\
\text { S7-54 } \\
\text { R1-56 } \\
\text { R1-56 } \\
\text { S7-54 } \\
\text { R1-56 } \\
\text { S7-54 } \\
\text { H5-52 } \\
\text { S7-54 } \\
\text { G1-25 } \\
\text { R1-51 } \\
\text { R2-50 } \\
\text { S7-81 } \\
\text { H5-52 }\end{array}$ & $\begin{array}{l}x \\
x \\
x \\
x \\
x \\
x \\
x \\
x \\
x \\
x \\
x \\
x \\
x \\
x \\
x \\
x \\
x \\
x \\
x\end{array}$ & & & \\
\hline & A3-88 & $x$ & & & \\
\hline
\end{tabular}

